JiSEA
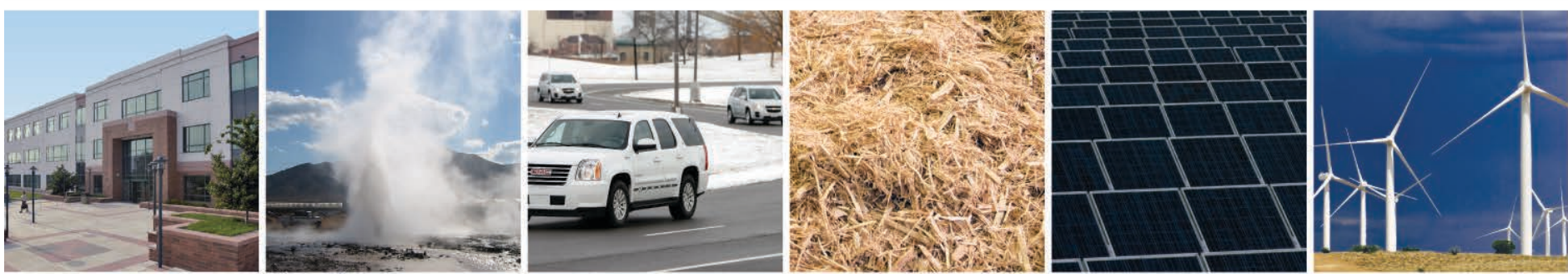

\title{
Summary Report of the INL- JISEA Workshop on Nuclear Hybrid Energy Systems
}

Mark Antkowiak and Mark Ruth National Renewable Energy Laboratory

Richard Boardman, Shannon Bragg-Sitton, Robert Cherry, and Lee Shunn Idaho National Laboratory

The Joint Institute for Strategic Energy Analysis is operated by the Alliance for Sustainable Energy, LLC, on behalf of the U.S. Department of Energy's National Renewable Energy Laboratory, the University of Colorado-Boulder, the Colorado School of Mines, the Colorado State University, the Massachusetts Institute of Technology, and Stanford University.

Technical Report

NREL/TP-6A50-55650

July 2012

Contract No. DE-AC36-08G028308 


\title{
Summary Report of the INL- JISEA Workshop on Nuclear Hybrid Energy Systems
}

\author{
Mark Antkowiak and Mark Ruth \\ National Renewable Energy Laboratory \\ Richard Boardman, Shannon Bragg-Sitton, \\ Robert Cherry, and Lee Shunn \\ Idaho National Laboratory
}

Prepared under Task No. 6A50.1027

The Joint Institute for Strategic Energy Analysis 15013 Denver West Parkway Golden, Colorado 80401 303-275-3000 • www.jisea.org
The Joint Institute for Strategic Energy Analysis is operated by the Alliance for Sustainable Energy, LLC, on behalf of the U.S. Department of Energy's National Renewable Energy Laboratory, the University of Colorado-Boulder, the Colorado School of Mines, the Colorado State University, the Massachusetts Institute of Technology, and Stanford University.

JISEA $^{\circledR}$ and all JISEA-based marks are trademarks or registered trademarks of the Alliance for Sustainable Energy, LLC.

\section{Technical Report}

NREL/TP-6A50-55650

July 2012

Contract No. DE-AC36-08G028308 


\section{NOTICE}

This report was prepared as an account of work sponsored by an agency of the United States government. Neither the United States government nor any agency thereof, nor any of their employees, makes any warranty, express or implied, or assumes any legal liability or responsibility for the accuracy, completeness, or usefulness of any information, apparatus, product, or process disclosed, or represents that its use would not infringe privately owned rights. Reference herein to any specific commercial product, process, or service by trade name, trademark, manufacturer, or otherwise does not necessarily constitute or imply its endorsement, recommendation, or favoring by the United States government or any agency thereof. The views and opinions of authors expressed herein do not necessarily state or reflect those of the United States government or any agency thereof.

Available electronically at http://www.osti.gov/bridge

Available for a processing fee to U.S. Department of Energy and its contractors, in paper, from:

U.S. Department of Energy

Office of Scientific and Technical Information

P.O. Box 62

Oak Ridge, TN 37831-0062

phone: 865.576 .8401

fax: 865.576 .5728

email: mailto:reports@adonis.osti.gov

Available for sale to the public, in paper, from:

U.S. Department of Commerce National Technical Information Service 5285 Port Royal Road Springfield, VA 22161 phone: 800.553 .6847 fax: 703.605.6900

email: orders@ntis.fedworld.gov

online ordering: http://www.ntis.gov/help/ordermethods.aspx

Cover Photos: (left to right) PIX 12721, PIX 13995, @ GM Corp., PIX 16161, PIX 15539, PIX 16701

Printed on paper containing at least $50 \%$ wastepaper, including $10 \%$ post consumer waste. 


\section{Acknowledgments}

This report summarizes a workshop jointly sponsored by the Joint Institute for Strategic Energy Analysis (JISEA) and the Idaho National Laboratory (INL). The authors would like to thank all the participants for their presentations and insights during the workshop. This workshop report is also being published as an INL report with the following INL report number: INL/EXT-1226551. 


\section{Abstract}

Hybrid energy systems utilize two or more energy resources as inputs to two or more physically coupled subsystems to produce one or more energy commodities as outputs. Nuclear hybrid energy systems can be used to provide load-following electrical power to match diurnal to seasonal-scale changes in power demand or to compensate for the variability of renewable wind or solar generation. To maintain economical, full rate operation of the nuclear reactor, its thermal energy available when power demand is low could be diverted into making synthetic vehicle fuels of various types. The Institute for Nuclear Energy Science and Technology (INEST) ${ }^{1}$ and the Joint Institute for Strategic Energy Analysis (JISEA) ${ }^{2}$ co-sponsored an international workshop to identify research topics important in advancing the potential use of hybrid systems with a specific focus on nuclear-renewable hybrid systems. The workshop included presentations ranging from energy challenges and research and development (R\&D) directions being pursued by nations to multiple options for hybrid systems. Those options include one that is being commercialized to other opportunities and analysis results quantifying them. The workshop also involved two breakout sessions — one focused on thermal energy management issues especially at unit-operation scale and the second focused on system operations issues including system controls, regulatory issues, technical and economic analysis, and market challenges. A discussion involving the full group focused on more general issues such as societal involvement and participation. Key criteria for selecting hybrid energy system projects and metrics for comparing them were also identified by the full group. The workshop's findings are being used initially by INEST to define topics for a research preproposal solicitation.

\footnotetext{
${ }^{1}$ INEST is a joint alliance between the Idaho National Laboratory and five partner universities: the Massachusetts Institute of Technology, North Carolina State University, The University Of New Mexico, Oregon State University, and the Ohio State University.

${ }^{2}$ JISEA is operated by the Alliance for Sustainable Energy, LLC, on behalf of the National Renewable Energy Laboratory, the University of Colorado-Boulder, the Colorado School of Mines, Colorado State University, the Massachusetts Institute of Technology, and Stanford University.
} 


\section{Introduction and History}

Hybrid energy systems utilize two or more energy resources as inputs to two or more physically coupled subsystems to produce one or more energy commodities as outputs. These energy conversion subsystems take an energy form, typically a primary resource such as wind's kinetic energy or the chemical energy in coal, and process it into a more generally useful energy product such as electricity or vehicle fuel, which can then be used to provide energy services such as cooling or transportation. The benefits generated by hybrid operation can include higher overall energy usage efficiency, better utilization of capital equipment, reduced emissions [especially of carbon dioxide $\left(\mathrm{CO}_{2}\right)$ ], and use of domestic resources rather than imported petroleum to make vehicle fuel.

Hybrids can be steady-state systems; for example, using hydrogen generated by nuclear-powered electrolysis to provide additional chemical energy to a coal-to-liquids process, thereby reducing overall $\mathrm{CO}_{2}$ emissions. Hybrid systems can also operate transiently; for example, using a nuclear power plant to make electricity during the day but diverting its thermal generation capacity unneeded at night to a synthetic fuels process such as natural gas conversion to synthetic gasoline. Energy storage systems can be incorporated into transient hybrid energy systems to improve their ability to respond to dynamic energy supply or demand changes and into steadystate systems to allow for production variations with constant demand.

Idaho National Laboratory (INL) has conceived and analyzed hybrid energy systems for several years, primarily under Laboratory Directed Research and Development funding and with a focus on using a nuclear reactor as an energy source. Recent work has concentrated on systems that can provide load-following electrical power, allowing nuclear systems to meet electrical demand above base-load levels. The ability to follow normal diurnal transients of hours duration also allows these systems to provide substantial, if not complete, compensation of variations in the output of wind or solar generation facilities. In this way, both nuclear and variable renewable sources of low $\mathrm{CO}_{2}$ power can increase their contribution to meeting national power demand.

In recognition of this synergy, in September 2011, a workshop to explore cooperative nuclearrenewable power generation was organized by the Joint Institute for Strategic Energy Analysis (JISEA) with INL, among numerous others, attending. JISEA is a cooperative venture of the National Renewable Energy Laboratory (NREL), the University of Colorado-Boulder, the Colorado School of Mines, Colorado State University, the Massachusetts Institute of Technology (MIT), and Stanford University that provides in-depth analysis of energy policy options. NREL itself has a long history of work in developing and evaluating renewable energy systems of many types. The consensus of that meeting was that there were significant opportunities for the two technologies to support each other.

Also during mid-2011, INL began organizing a new Center of Research and Education (CORE) within its Institute for Nuclear Energy Science and Technology (INEST). INEST supports academic research done collaboratively with an INL researcher in defined areas of nuclear engineering, with this CORE, the fifth one established, being focused on nuclear hybrid energy systems. As part of establishing this CORE, an international workshop to identify appropriate research directions was planned for spring 2012. Because this workshop was recognized as a natural continuation of the discussions started at the JISEA meeting, INL and JISEA jointly planned it. 
This report documents the results of that workshop, which was held on April 3-4, 2012, in Salt Lake City, Utah. About 40 people representing national laboratories, universities, and energy companies attended from across the United States and from China and France. The agenda and list of attendees are included as Appendices A and B. 


\section{Overview Presentations}

The program began with several presentations providing an overview of already established activities similar to or supportive of hybrid energy systems. The full presentations are available at https://inlportal.inl.gov/portal/server.pt?tbb=hybrid. Key points from them and the associated discussions are summarized here.

\subsection{Grand Energy Challenges}

Doug Arent of JISEA discussed the Grand Energy Challenge, observing that market, regulatory, and political challenges are greater than technical ones. Technology and informatics are changing the ways energy is used. The enhanced information exchange and expectation for transparency via social networks could potentially have huge effects on energy, particularly the social acceptance of energy sources, transmission and other infrastructure, and utilization. Getting leaders to address grand challenges requires that they hear from many trusted messengers. Thus, the availability of credible, objective data, information, and tools is critical to inform energy decisions at local, regional, national, and global levels. International partnerships bring considerable value because technology supply chains are global and precompetitive research and development $(\mathrm{R} \& \mathrm{D})$ can benefit all parties. There are many drivers to energy change, including energy security, environmental impacts, and economics, and the relative importance among these factors is location and context dependent. In many examples, local issues such as air quality, water availability and quality, and local economic situation may be "closer to the political bulls-eye" than the global environment.

\subsection{A Wyoming Case Study}

The State of Wyoming was presented as a case study in energy development by Bob Ballard of the University of Wyoming, who was also representing the State of Wyoming and the Wyoming Business Council. Wyoming is the top state for total energy production (largely from coal) and is now tenth in the country in megawatts of wind capacity. This number has been increasing although they are constrained by transmission capacity. They are interested in combining renewable generation with other systems to be able to provide energy reliably to large industrial users. Since 2004, the university has committed \$228.6 million to energy research from various sources. The school has three focus areas:

- Unconventional reservoirs (tight gas, shale gas, oil shale, and residual oil zones)

- Climbing the value chain (adding value to existing resources and creating products and markets)

- Wind and solar energy (efficiency improvement, intermittency mitigation, and energy storage).

\subsection{Overview of Hybrid Systems in China}

An overview of energy research in China was given by Zhiyuan Zhu of the Chinese Academy of Sciences (CAS) Shanghai Branch. CAS has a broad program investigating renewable, fossil, and nuclear energy. Because the country has large reserves of coal, there is a major effort on coal-tochemicals conversion, as well as coal-to-liquid fuels. Recently the CAS has begun doing nuclear power research after five decades of not working in that area. Their nuclear focus is on thoriumfueled molten salt reactors (TMSR) (motivated by China's thorium reserves) and on accelerator driven systems. There is interest in producing hydrogen with a TMSR or with concentrating solar 
power (CSP), especially through the use of high temperature electrolysis. Their development timeline includes demonstration of 2, 10, and 100 MWe TMSRs in the years 2015, 2020, and 2030 , respectively. Hydrogen production ties to their interests in coal conversion and possible recycling of $\mathrm{CO}_{2}$ as a carbon source for chemical syntheses. In response to questions, Zhu noted that reducing water usage for either cooling or processing has not been an objective and that industrial participation in chemical process development becomes necessary at the demonstration scale because CAS cannot afford to do those projects by itself.

\subsection{An Industrial Perspective on Hybrid Energy}

An industrial perspective on hybrid systems was presented by Max Peter of GE Global Research. GE has recently introduced a commercial hybrid system consisting of a natural gas combined cycle power plant with additional heat input from CSP. Their observations about such systems include that plant outputs should be controllable, hybrids must demonstrate that they do not disrupt operations or revenue of the component systems, performance guarantees are challenging for hybrids, and having a single system integrator as a turnkey provider may be necessary to overcome technological stovepipes until these systems are more mature and proven.

\subsection{Summary of 2011 Nuclear-Renewable Synergies Workshop}

Mark Ruth of NREL provided a summary of the fall 2011 JISEA workshop on synergies between nuclear and renewable energy. The workshop's objective was to assemble experts to identify and prioritize potential synergies between nuclear and renewable energy and to identify potential leveraging opportunities. Opportunities were identified and prioritized. Breakout discussion groups were organized for each of the three high priority topics: hybrid energy systems, value proposition/business case, and energy for transportation. Each group identified the potential, challenges, priority analysis needs, and priority R\&D opportunities in their area. The workshop report is published at www.nrel.gov/docs/fy12osti/52256.pdf. The workshop was considered valuable because it assembled members from various technology and policy communities and provided impetus for collaboration. Integrating ideas across these disciplines is key to building support for the idea of hybrid energy systems. One of the purposes of the Salt Lake City workshop was to integrate a range of ideas for hybrid energy systems and determine R\&D needs.

\subsection{Nuclear-Renewable Hybrid Systems with Thermal Energy Storage}

Paul Denholm of NREL discussed the role of thermal energy storage in nuclear-renewable hybrid systems. Over $60 \%$ of electrical demand can be met by base-load or nearly base-load systems (those with over $96 \%$ capacity utilization), a regime well suited to nuclear plants. However, the remaining $40 \%$ requires systems that can be operated economically on a part-time basis. Adding variable renewable generation to the mix increases the need for flexible, part-time generation. Even if a nuclear plant is agile enough to follow and counterbalance the variability of wind, operating at less than full rates is not economically attractive. Adding thermal storage to a system addresses both of these issues. However, NREL has not done an economic analysis of the cost of thermal storage.

\subsection{Nuclear Reactor Technologies for Hybrid Applications}

Michel LeComte, recently retired from AREVA, provided a French perspective. France has no coal, oil, or gas of its own so it depends on nuclear, wind, and hydro. They are very concerned about the variable production from renewable sources. The northern Germany grid system has a large fraction of renewable generation and is already becoming unstable, threatening 
destabilization of neighboring grid systems. Nuclear hybrid energy systems can help stabilize the grid, remaining economical by making easily stored liquid synthetic fuels when their output is not needed for electricity production. Liquid fuels will be required for quite some time (e.g., for aviation). Even if those synfuels are expensive, perhaps the equivalent of petroleum at $\$ 200$ per barrel, having the technology developed and operating puts a strategically valuable known cap on the economic damage that can be inflicted on a country by petroleum supply interruptions. Over the long run, the development of nuclear plants should optimize both core physics (for generating medical or industrial isotopes, or 'burning' nuclear byproducts) and energy production (as heat, power, or both). LeComte noted that small nuclear plants are capital intensive and regular-sized plants are cheaper to run than small plants. However, it is expensive to transport high-temperature heat for use in a hybrid system so the chemical process is best built adjacent to the heat source. The challenge is to make efficient and effective chemical plants to be part of nuclear hybrid systems.

\subsection{Prospects for Nuclear Hybrid Systems}

A thorough overview of many possible applications of nuclear heat was provided by Henri Safa of Commissariat à l'énergie atomique et aux énergies alternatives (CEA), the French nuclear and alternative energy agency. Hydrogen production using the sulfur-iodine process was explored by a team of CEA, General Atomics, and Sandia National Laboratory but was projected to be significantly more expensive than high temperature steam electrolysis. Second generation biofuels are under active research in France. Two of the three candidate biofuel processes are thermochemical routes based on synthesis gas. The SYNDIESE project will demonstrate the complete biomass-to-liquids conversion, including a world's first demonstration of the use of external hydrogen to improve process efficiency. A survey of industrial energy use in France showed that about $40 \%$ of consumption is heat at less than $400^{\circ} \mathrm{C}$. The energy needs of a large oil refinery, including power, steam, hydrogen, and water, could be met by a single $600 \mathrm{MWe}$ sodium-cooled fast reactor operating at $500-600^{\circ} \mathrm{C}$. Finally, district heating is an attractive and growing market suitable for low-temperature nuclear heat. Supplying this heat from the lowtemperature end of a power cycle reduces electricity production, but this is more than offset by the revenues from supplying steam at 2 bar pressure for heat. This low temperature heat can be economically transported for long distances, with one example presented assuming $150 \mathrm{~km}$. All of these applications have the additional benefit of greatly reduced $\mathrm{CO}_{2}$ emissions compared to their conventional counterparts.

\subsection{NuRenew: Hybrid Nuclear-Renewable Energy Park}

Bojan Petrovic of Georgia Tech made a brief presentation on NuRenew, a concept for an energy park that incorporates a molten-salt-cooled nuclear reactor, molten-salt-based CSP, and moltensalt-based thermal energy storage. The reactor could use thorium as fuel to address waste management issues. This hybrid energy system would provide electricity, transportation fuel, and high temperature process heat at about $600^{\circ} \mathrm{C}$. It would enable re-purposing of fossil plant sites and coal infrastructure and would facilitate accelerated deployment of CSP.

\subsection{Nuclear-Renewable Production of Hydrogen and Syncrude}

Charles Forsberg of MIT described two nuclear hybrid concepts producing hydrogen or synthetic crude oil from oil shale. The hydrogen system uses a high temperature electrolyzer to split water when excess power generation capacity is available, primarily for use in industrial markets. When peak power is needed, the electrolyzer is run in reverse to function as a fuel cell, generating power from the stored hydrogen. The dual functions improve the economics by using 
one device for both hydrogen production and peak electricity generation. In the oil shale system, a nuclear power plant generates load-following low- $\mathrm{CO}_{2}$ electricity, displacing an equivalent amount of fossil-fired, $\mathrm{CO}_{2}$-emitting power generation. When that nuclear electricity is not needed, the heat that would be used to generate it is instead diverted into heating a subsurface oil shale deposit. After several years of retorting at high temperature, the hydrocarbons in that deposit can be withdrawn as a synthetic crude oil. The credits for $\mathrm{CO}_{2}$ reductions obtained during the nuclear electricity production can be applied to the syncrude to allow it to meet low emissions standards increasingly being proposed and applied to vehicle fuels. In developing hybrid energy systems such as these, the institutional challenges of crossing established regulatory and business borders might equal the technical problems.

\subsection{Nuclear Hybrid Systems to Offset Variability of Wind-Generated Electricity}

As the last technical talk before the breakout sessions, Richard Boardman of INL briefly described four increasingly complex hybrid system configurations that might be used to offset the variability of wind energy generation. Three of the four had a fossil-fired power plant as the heat source. Although nuclear systems would be the best way to avoid $\mathrm{CO}_{2}$ emissions, it is likely that initial hybrid systems will be fossil-fired to simplify those demonstrations and to allow continued development and licensing of the next generation of reactors. 


\section{Breakout Sessions}

The attendees broke into two self-selected groups for in-depth discussions. One group, moderated by Shannon Bragg-Sitton of INL, covered thermal energy management issues with a focus on technology at the scale of unit operations. The second group, moderated by Robert Cherry of INL, covered system operations issues such as technical and economic analysis, system controls, and regulatory and market challenges. Their major points were reported to the full workshop using the presentations in Appendices C and D, respectively.

\subsection{Thermal Energy Management}

The thermal energy management group covered a range of topics including possible applications of hybrid systems, issues with use of a nuclear reactor, transport and storage of thermal energy, chemical conversion processes, and material problems at high temperatures. Their resulting list of priority research topics is reported in Appendix C. It includes equipment coupling, thermal energy storage (including the tradeoff of additional storage versus faster system dynamics to enable better load-following), developing methods for carbon-free hydrogen production, identifying additional ways to exploit excess heat or electricity, and development of heat transfer fluids.

\subsection{System Operations}

The system operations group identified technical gaps in a variety of system-level issues. A partial list of the R\&D recommended to address these gaps includes additional economic and feasibility studies on alternative configurations, rationalization of the different methods and criteria for assessing projects used by the different industries that currently run the technologies that would be combined in a hybrid system, coordination of the multiple control systems in interacting subcomponent processes, the role of energy storage capacity in improving dynamic response, and understanding what options (including retrofits of existing power plants) are feasible for demonstration in the near-term and how they might facilitate eventual commercialization. The topic of the interplay between energy storage and dynamic responsiveness was independently identified by both breakout groups. 


\section{Group Discussion}

The first round of discussion covered topics that might have been missed or not fully described by the two breakout groups. Collected into related issues, these included:

What problem are we trying to solve? Hybrid system developers need to clarify their objective(s), which might include lower cost of energy, reduced imports, or energy security. They must understand and explain the solutions in a compelling manner. Transportation fuels will be important because purchases of oil from foreign countries reduce job opportunities here by sending dollars overseas. Stable and predictable fuel prices are also important. There are other opportunities related to generation and use of heat, especially using low-temperature heat for space and district heating and developing ways to do load-leveling with either thermal or nonthermal (such as wind) energy sources. Addressing complex mixed regulatory issues so these systems can be built will be difficult. Careful validation of analysis methods developed to let scaled-down tests be applied to novel fullscale designs will be important.

Who should participate? Industry buy-in will be important because they will commit to and execute the projects. The chemical or fuel outputs of hybrid energy systems will have to be integrated into the chemical and petrochemical supply chains, so those industries as well as traditional fossil energy firms that operate in these markets could productively be involved. The solar photovoltaic industry also has variability problems that might be addressed by hybrid energy systems. Other potentially interested industries should be identified. The Department of Energy program to develop high-temperature gas-cooled reactors has been in recent years pursuing a similar technology development and commercialization effort. Understanding their experience could be useful.

What communications and outreach are needed? The policy world is the means by which the government will learn of and support hybrid energy system development and implementation. However, policy analysts as a group lack an understanding of technical issues. Hybrid system supporters need to provide the policy world with a simple cohesive message that provides answers to current problems and can be communicated to Congress and the administrative branch. Recalling President Obama's statement that the country's energy problems require an "all of the above" approach, hybrid systems might represent "integration of all of the above." Ultimately, though, the energy industry must make the decision to build and operate hybrid energy systems, possibly in response to policy incentives.

Because many different hybrid energy systems with different combinations of technologies are possible, it is necessary to have criteria for selecting those that are most attractive. This selection will naturally depend on the stakeholders participating. Metrics for these criteria for various hybrid system configurations will have to be developed. The criteria proposed included the following, which have been collected into categories of related issues: 
Development risks: Managing development risk, capacity for staged demonstration and evolutionary development, limited complexity, good controllability, and near-term deployability.

Project economics: Cost (business case, capital cost, return on investment), ability to finance large capital costs, initial deployment location (optimal siting to address the multiple feed and product streams, choice of building in developed versus developing countries), and end-user needs.

Sustainability issues: Greenhouse gas emissions, fossil energy use, feedstock consumption, water withdrawal and consumption, long-term availability of resources, and land requirements.

National policy issues: Value to the nation outside of immediate project economics, energy security, flexibility to use different feeds or make different products that might be mandated by future policies, value in niche markets of a few such plants, and transparency in reaching policy decisions.

In addition to the characteristics of the possible configurations, the choice of specific primary energy sources or energy products is clearly important. The workshop attendees proposed candidates that may be of greater initial interest because of regional needs or available resources. These sources and applications include:

- Sources

- An architecture that would enable renewable energy use on the grid at levels above $25 \%$

- Geothermal hybrid systems must address economic problems resulting from low temperatures and small plant capacities

- Lower capital cost, small modular nuclear reactors

- Natural gas as a plentiful, low-cost input used for thermal energy or for feedstock to make synthetic fuels or hydrogen

- Retrofit of hybrid systems onto existing plants

- General Electric natural gas/solar concept but with integrated energy storage

- Existing coal coordinated with wind

- Coal with solar thermal

- Products

- Early systems using combined heat and power with thermal storage

- Replacing power production from aging coal plants

- Desalination

- Synthetic fuel production via nuclear power

- Use of $\mathrm{CO}_{2}$ captured from fossil-fired power plants to make synfuels. 


\section{Resulting Call for Proposals}

Immediately after the workshop, the results were used to generate a call for INEST preproposals related to nuclear hybrid energy systems. The text of that call is presented in Appendix E. The requested topic areas were:

- Nuclear hybrid design concepts and analyses to identify and understand alternative new configurations

- Temperature boosting to raise the relatively low temperature $\left(270-300^{\circ} \mathrm{C}\right)$ thermal output of light water reactors to higher levels, $500-800^{\circ} \mathrm{C}$ or more, to make that heat more generally useful for synthetic fuels processes; many of the most advanced concepts for small modular reactors are pressurized light water reactors

- Hydrogen production using nuclear energy, possibly combined with concepts from the first two topics in this list, would be useful for synfuel production

- Policy strategies for integrating the disparate technologies and regulatory paradigms associated with complex, integrated nuclear hybrid systems and that address key nontechnical challenges to fielding such a system. 


\section{Appendix A. Workshop Agenda}
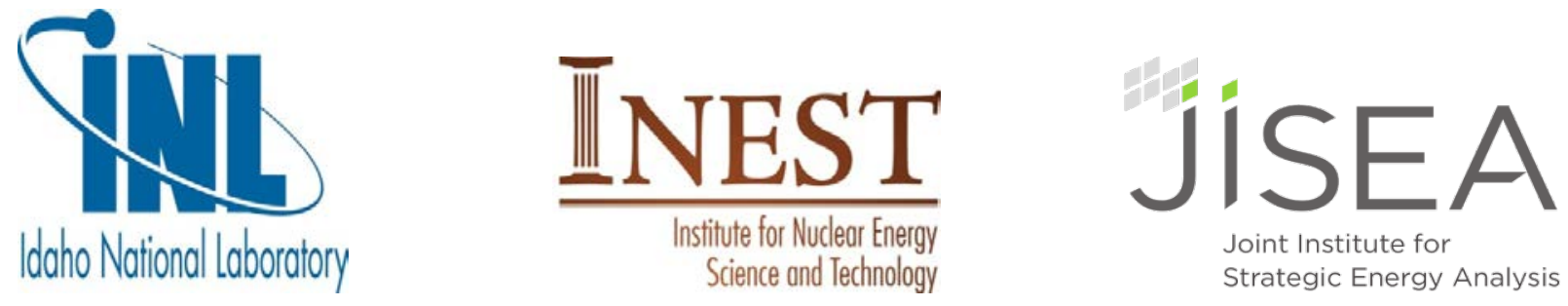

\section{Hybrid Energy Systems Workshop}

April 3-4, 2012

Salt Lake City Marriott Downtown

Day 1

7:30 am Breakfast/Welcoming Remarks

8:15 am Participant Introductions

8:30 am Overview of INEST and JISEA

8:45 am Grand Energy Challenges

9:00 am A Wyoming Case Study

9:25 am Overview of Hybrid Systems in China

9:50 am An Industrial Perspective on Hybrid Energy

10:15 am Break

10:30 am Summary of 2011 JISEA Workshop

10:55 am Nuclear Power Plants with Thermal Energy Storage

11:30 am Nuclear Reactor Technologies for Hybrid Applications

11:45 am Prospects for Nuclear Hybrid Systems
Steve Aumeier (INL)

Charles Forsberg (MIT)

All

Marsha Lambregts (INEST)

Doug Arent (JISEA)

Doug Arent (JISEA)

Bob Ballard (U of Wyoming)

Zhiyuan Zhu (Chinese

Academy of Sciences)

Max Peter (General

Electric)

Mark Ruth (NREL)

Paul Denholm (NREL)

Michel LeComte (AREVA)

Henri Safa (CEA) 


\section{2:10 pm Working Lunch}

NuRenew: Hybrid Nuclear-Renewable Energy

Park

Nuclear-renewable Production of $\mathrm{H}_{2}$ and

Syncrude

INL Hybrid Energy Program

1:30 pm Break

1:40 pm Outline "Example” Hybrid Energy Systems

1:50 pm Discussion Objectives

2:00 pm Group Discussion

Breakout 1: Thermal Energy Management

Breakout 2: System Operations

- Identify R\&D challenges and technology gaps

- Prioritize challenges

3:15 pm Break

3:30 pm Group Discussion

For each topic area:

- Identify research activities

- Prioritize research activities

4:50 pm Discussion Wrap-up and Summary

5:00 pm Reception and Networking Opportunity

Casual Discussion of Break-out Results

Day 2

7:30 am Breakfast/Discussion of Break-out Results

System Level Control System Needs

9:30 am Panel Discussion: Successful Public/Private Partnerships

10:00 am Opportunities for Research Partnerships

- INEST and NEUP
Bojan Petrovic (Georgia

Tech)

Charles Forsberg (MIT)

Richard Boardman (INL)

Richard Boardman (INL)

Shannon Bragg-Sitton (INL)

Shannon Bragg-Sitton (INL)

Robert Cherry (INL)

Richard Boardman (INL)

Shannon Bragg-Sitton (INL)

Robert Cherry (INL)

Moderator: Richard

Boardman (INL) 
- JISEA

- LDRD program

- Program development funds

- Faculty-Staff exchanges

- Public/Private partnerships

- NEUP proposal highlights "Potential Characterization \& Operation of Hybrid Heat Transport \& Energy Conversion Systems Using Intelligent Control" (Akira Tokuhiro)

11:00 am Closing Remarks

11:15 am Break/Networking and Individual Discussions

12:00 pm Steering Committee Meeting
Marsha Lambregts (INEST)

Doug Arent (JISEA)

Steve Aumeier (INL) 


\section{Appendix B. Attendees}

\section{Hybrid Energy Systems Workshop}

\section{Attendees List}

\section{April 3-4, 2012}

\begin{tabular}{|c|c|c|c|}
\hline Mark & Antkowiak & NREL & Mark.Antkowiak@NREL.gov \\
\hline Doug & Arent & JISEA & pamela.lee@nrel.gov \\
\hline Steven & Aumeier & INL & steven.aumeier@inl.gov \\
\hline Robert & Ballard Jr & $\mathrm{U}$ of WY & rballar2@uwyo.edu \\
\hline Heng & Ban & Utah State University & heng.ban@usu.edu \\
\hline James & Bartis & RAND & bartis@rand.org \\
\hline David & Bell & $\mathrm{U}$ of WY & davebell@uwyo.edu \\
\hline Richard & Boardman & INL & richard.boardman@inl.gov \\
\hline Shannon & Bragg-Sitton & INL & shannon.bragg-sitton@inl.gov \\
\hline Robert & Cherry & INL & robert.cherry@inl.gov \\
\hline Benjamin & Cross & Savannah River Nat. Lab & Ben.Cross@srnl.doe.gov \\
\hline Larry & Demick & INL & Laurence.Demick@inl.gov \\
\hline Paul & Denholm & NREL & paul.denholm@nrel.gov \\
\hline Linda & Elliott & INL & linda.elliott@inl.gov \\
\hline Marvin & Fielding & Schiess \& Associates & mfielding@schiesseng.com \\
\hline Charles & Forsberg & MIT & cforsber@mit.edu \\
\hline Humberto & Garcia & INL & Humberto.Garcia@inl.gov \\
\hline Maximilian & Gorensek & SRNL & maximilian.gorensek@srnl.doe.gov \\
\hline James & Herzog & INL & james.herzog@inl.gov \\
\hline John & Hess & INL & jrichard.hess@inl.gov \\
\hline Robin & Hurless & $\mathrm{U}$ of WY & rob.hurless@wyo.gov \\
\hline Jeffrey & King & Colorado School of Mines & kingjc@mines.edu \\
\hline Marsha & Lambregts & INL & marsha.lambregts@inl.gov \\
\hline Michel & LeCOMTE & AREVA & Michel.lecomte.ext@areva.com \\
\hline Gloria & Newberry & INL & gloria.newberry@inl.gov \\
\hline John & Nowoslawski & State of Utah & jnowoslawski@utah.gov \\
\hline Andrew & Peter & GE Global Research & peter@research.ge.com \\
\hline Bojan & Petrovic & Georgia Tech & bojan.petrovic@gatech.edu \\
\hline Craig & Rieger & INL & craig.rieger@inl.gov \\
\hline Mark & Ruth & NREL & mark.ruth@nrel.gov \\
\hline Piyush & Sabharwall & INL & Piyush.Sabharwall@inl.gov \\
\hline Henri & SAFA & CEA & henri.safa@cea.fr \\
\hline Christopher & Saffron & MSU & saffronc@msu.edu \\
\hline Beth-Anne & Schuelke-Leech & The Ohio State Univ & schuelke-leech.1@osu.edu \\
\hline Vijay & Sethi & Western Research Institute & vsethi@uwyo.edu \\
\hline
\end{tabular}




\begin{tabular}{|l|l|l|l|}
\hline Carl & Stoots & INL & carl.stoots@inl.gov \\
\hline Xiaodong & Sun & The Ohio State University & sun.200@osu.edu \\
\hline Doug & Taylor & INL & doug.taylor@inl.gov \\
\hline Akira & Tokuhiro & University of Idaho & tokuhiro@uidaho.edu \\
\hline Pavel & Tsvetkov & Texas A\&M University & tsvetkov@tamu.edu \\
\hline Vivek & Utgikar & University of Idaho & vutgikar@uidaho.edu \\
\hline James & VanDerwerken & GE Global Research & vanderwerken@ge.com \\
\hline Alan & Walker & USTAR & alanjwalker@utah.gov \\
\hline Joshua & Walter & TerraPower & jwalter@terrapower.com \\
\hline Charles & Weingartner & DOE-ID & weingacb@id.doe.gov \\
\hline & & Shanghai Branch, Chinese & \\
Zhiyuan & Zhu & Academy of Sciences & zhuzy@shb.ac.cn \\
\hline
\end{tabular}




\section{Appendix C. Thermal Management Breakout Discussion}

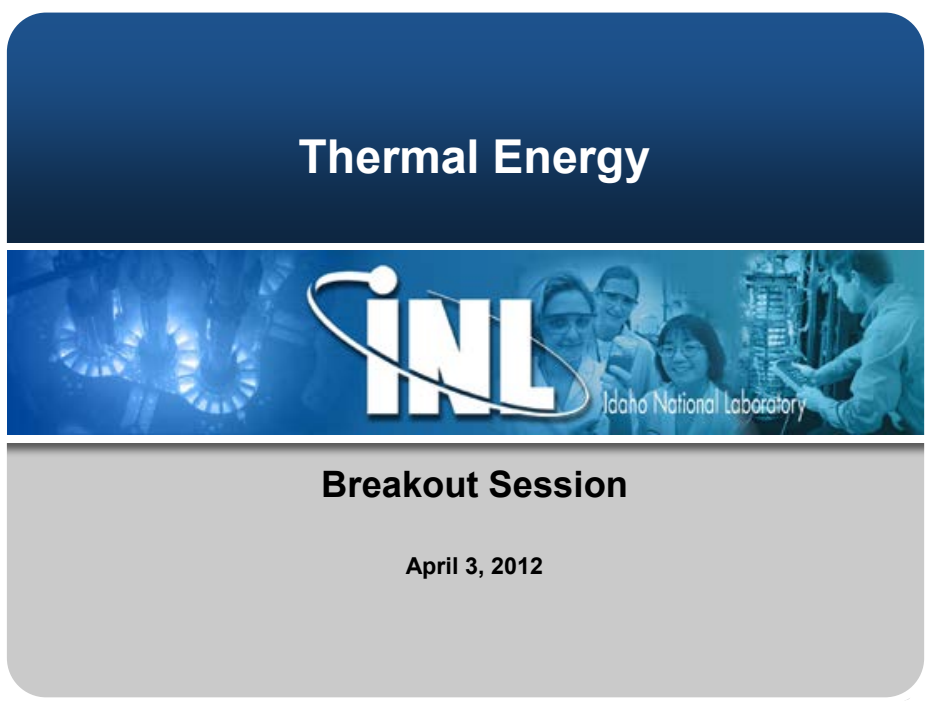

\section{Discussion Points}

- Base Thermal Generation

- Reactor Concepts / Modularization

- Fossil and Renewable Concepts

- Thermal Energy Transport

- Heat Deposition to Process

- Thermal Hydraulics

- Heat Exchange

- Heat Upgrading

- Thermal Energy Storage

- Chemical Energy Conversion

- Hydrogen Generation

- Liquid Fuel Production

- Fossil Fuel Extraction and Processing

- Materials \& Equipment Fabrication

- High Temperature Systems

- Component Fabrication 
What is the MARKET size for each "problem"?

- Dictates R\&D funds available

What can be uniquely solved by hybrid energy systems?

Problems to address:

- Need for hydrogen production

- Clean process (reduced GHG emissions)

- Consider resource needs / availability (i.e. water)

- Uprating of fuels

- Shale oil extraction - huge market

- Increased efficiency

- Multi-purpose reactors: Entry of nuclear energy into the transportation industry

\section{Research Objectives}

- Carbon free electricity production

- Improved fossil energy use

- Infrastructure development for large-scale production of a commodity that can be transported, stored and used as a feedstock in a carbon-free fashion

\section{Base Thermal Generation}

- Reactor selection cannot be custom for a given process

- Generally assume steady state only: Desire to place flexibility

downstream of reactor (chemical plant or thermal storage)

- Resource utilization / siting needs

- Trade study:

Address what concepts are feasible when coupled with energy storage and chemical applications (consider dynamic linkages)

- Trade study:

Thermally coupling of various reactor types to different processes economics, licensing, risk assessment, technical issues, siting..

- Low temperature generation: (nearer term applications)

- Possibly more closely coupled than high T generation systems

- Gap: Is the heat of sufficient quality for desired tasks?

- Gap: Temperature upgrading

- High temperature generation:

- Higher efficiency

- Possibility for air cooling

- Gap: Efficient heat transmission 
- Thermal coupling

- Importance of thermal interface - possible scaled demonstration of thermal coupling solutions?

- Need a clear understanding of customer needs, market needs

- Heat upgrading trade study: Methods to increase steam temperature to enable more process applications

- Different technology routes depending on scale of the operation

- Heat exchanger designs

- Working fluid characterization

- Feedback / sub-system interaction

- Nuclear plant - chemical plant feedback and sub-system prioritorization (NPP - grid - CP)

- Safety issues, licensing mandates

- Possible early demonstration:

Nuclear plant coupled to a chemical process (single input I single output)

\section{Thermal Energy Storage}

- What is the thermal energy storage capacity requirement?

- General Requirements

- Enable load following

- Maintain consistent reactor inlet temperature

- Match sub-system time constants (energy storage, reactor, chemical plant, grid)

- Provide high density storage medium (e.g. liquid hydrocarbons)

- Possible solutions

- Molten salts as storage medium (leverage solar thermal programs)

- Phase change materials with high heat capacity

\section{- Research Areas:}

- Thermal storage systems specifically coupled to a reactor

- Development of highly dense storage systems

\section{Chemical Energy Conversion}

- Negative electric prices (i.e. paying the grid for power) what can we do with the excess electricity?

- Reduce capital cost of processes

- Commodity production and storage - what makes sense?

- Methanol, ammonia, hydrogen, syncrude...

Research Areas:

- Hydrogen generation for multiple applications

- Hydrogen storage and transport (gas vs. liquid)

- Electrolysis (QC, cell durability, scale-up, on-line maintenance)

- GOAL: Reduce capital costs for electrolyzers

- CO production

$-\mathrm{CO}_{2}$ source?

- Liquid Fuel Production

- Require $\mathrm{H}_{2}$ for higher density fuel and syngas production

- Fossil Fuel Extraction and Processing 


\section{Materials and Equipment Fabrication}

- High temperature systems face increased materials challenges

- Concern: Material availability and qualification

- Research areas:

- Working fluids:

- Analysis of working fluid chemistry and properties and effect of

structural materials

- Process control - impurities, chemistry control

- Freeze-thaw issues for some working fluids (i.e. molten salts)

- Heat exchanger design (conventional vs. advanced)

- Stress-corrosion cracking

- Design reliability

- Equipment for heat transport over long distances

\section{Identified Key Research Areas}

- NHES sub-system interfaces - specific focus on coupling

- Thermal coupling of different reactor concepts

- Dynamic links for different reactor designs

- Economics and technical challenges of transporting heat (high vs. low T, distances)

- Thermal storage options - requirements, scalability for demonstration (high volume to surface area ratio)

- Parametric and sensitivity study for working fluid selection, material compatibility

- Integrated system operations to demonstrate system coupling solutions, thermal energy transfer, storage, etc.

- What can be learned from a small-scale hardware demonstration?

- What is the scalability of sub-systems?

- What will provide reasonable accuracy / understanding of system operation?

\section{Priority Research Areas}

- Equipment Coupling

- Thermal Energy Storage - coupling to a nuclear reactor (consideration of temperature and capacity)

- Methods for efficient carbon-free hydrogen production (sustainable and economical)

- Methods to exploit excess heat / excess electricity

- Heat transfer fluid development, characterization 


\title{
Appendix D. System Operations Breakout Discussion
}

\author{
Modeling, Integration, Optimization
}

Microeconomic Analysis (to guide investments in R\&D)

GAP: Additional objective economic feasibility studies need to be done

RESEARCH TOPIC: Analysis of inputs and outputs and capital for the potential HES (identify near-term winners with today's incentives and longterm, high payoff)-including energy security, environments, social, political, economic, etc.

\section{Technical Analysis}

GAPS:

- Heuristics to prioritize and screen alternatives (development of criteria)

- Different industries coming together who have different basis for design and different systems analysis tools which must be integrated and used to model the whole system --Need improved computer simulation tools (e.g., need to be adapted to power systems-multi-domain dynamic analysis)

RESEARCH TOPIC:

- Assemble stakeholders to develop criteria and identify heuristics (prioritize)

- Develop open computational tool set for analysis of the dynamic system

\section{System Monitoring \& Control (Instruments \& Operators)}

\section{Human Factors}

GAP: Coordination between multiple control systems--interaction between the different systems

RESEARCH TOPIC: Preliminary investigation of current analogs - petrochemical plants or flight control systems

\section{Instrumentation}

GAP: Sensors needed to measure --- contamination leaking back into the nuclear side

RESEARCH TOPIC: Identification of issues that require sensors (e.g., contamination or interferences) and or interpretive algorithms (e.g., diagnostics/ prognostics)

Dynamic System Modeling

GAP: Lack of ability to predict and model the interaction of the application of the various systems you are using

RESEARCH TOPIC: Develop open computational tool set for analysis of the dynamic system (see above--repeat) 


\section{Grid Management}

Intermittent Generation

GAP: Need for stable output - how might HES be operated to stabilize the grid (responsive to changes in demand and variability)

RESEARCH TOPIC: Looking at HES in context of national grid management goals (relates to research bullet 1 above)

Electrical Power Transmission

GAP: Siting-using different resources, different products-how to optimize siting decisions

RESEARCH TOPIC: Computational/system model/matrix of the HES (providing the range of options) to increase understanding of how adding systems increase complexity (regional basis)

\section{Energy Storage/Batteries}

GAP: Determining storage levels (capacity) and which technologies should be used, what is sufficient?

RESEARCH TOPIC: Sweet spot analysis of storage capacity versus system flexibility/response

\section{Sociopolitical \& Financing Challenges}

\section{Regulatory/Licensing/Safety}

GAP: Different regulatory and design codes for nuclear, electrical and chemical

RESEARCH TOPIC: Identification of policy/regulatory conflicts and commonalities among the various agencies

\section{Market Challenges}

GAPS:

- Understanding of near-term options versus long-term options and emerging technologies and what steps are required to get commercial scale production

- Ability to retrofit versus new construction

RESEARCH TOPIC: Develop roadmap of technologies

\section{Life Cycle Assessment}

GAP: Lifecycle analysis of each system

RESEARCH TOPIC: Review status of baseline technology and LCAs (identify where they are today to do a comparative) 


\title{
Appendix E. INEST Call for Proposals on Nuclear Hybrid Systems
}

\author{
Institute for Nuclear Energy Science and Technology \\ 2013 LDRD Call
}

Point of Contact: Marsha Lambregts, 526-1336, Marsha.Lambregts@inl.gov

\begin{abstract}
Summary:
The Institute for Nuclear Energy Science and Technology (INEST) will sponsor and oversee laboratory directed research aligned with the strategies of four Centers of Research and Education (CORE): Fuel Cycle, Nuclear Fuels and Materials, Safety and Licensing, and Space Nuclear Power. Additional information about INEST and the COREs can be found at:

https://inlportal.inl.gov/portal/server.pt/community/institute for nuclear energy science and technology/ 692/home. The criteria to be used in selection of the LDRD proposals are:

Essential
\end{abstract}

1. Technical merit

2. Develop capabilities supportive of INEST CORE strategies

3. Strengthen collaborations with universities

Additional

4. Attract expertise to INL

5. Encourage student participation

Specific guidance in each area is provided below:

[Four other technical areas deleted here]

Nuclear Hybrid Energy Systems CORE LDRD Call

Contact: Steve Aumeier, 526-6997, Steve.Aumeier@inl.bgov

Estimated budget $\$ 250 \mathrm{~K}$ for FY2013

U.S. energy security objectives (DOE Report on the First Quadrennial Technology Review, September, 2011) highlight the need for lower carbon, domestic energy options for both stationary power generation and transportation systems. In the former, objectives call for deriving $80 \%$ of America's electricity from clean-energy sources by 2035, while improving the modularity, scalability, and infrastructure compatibility of clean-electricity-supply technologies and reducing greenhouse gas emissions by $83 \%$ by 2050 (from a 2005 baseline). Renewable electric generation and small modular nuclear reactors (SMRs) are each identified as a priority focus for clean power generation, with energy storage for excess power generation specifically mentioned as a need. Transportation system objectives are tied fundamentally to goals of reducing greenhouse gas emissions and reducing the import of oil sources from overseas. Resulting objectives cover multiple pathways, including vehicle efficiency, fuel switching (e.g., electric and hybridelectric vehicles, natural gas vehicles), biofuels, and synthetic fuels with low life-cycle carbon 
characteristics. Tangential to these outcomes are objectives to increase domestic manufacturing and export of U.S. manufactured products. Significant barriers to meeting these objectives include:

1. Large scale renewable electric generation can introduce significant intermittency in generation resulting in grid management, stability, and control challenges as well as resource utilization inefficiencies (low capacity factors);

2. Transportation fuels sourced from domestic carbon must have lower life-cycle greenhouse gas emissions than oil-derived fuels; electrification and natural gas vehicle introduction will take many years to fully deploy and will not displace the need for liquid transport fuels; cost effective biofuels production at scale will take much more time and development to realize;

3. Nuclear energy, including SMRs, deployed in present operational paradigms (baseload electricity generation) are fundamentally limited in their ability to impact the broad transportation market and do not enable greater penetration of renewable energy or management of the increasingly dynamic electric grid.

Proposals are thus encouraged in the following areas:

Nuclear Hybrid Design Concepts and Analyses: Proposed nuclear hybrid energy system architecture concepts and related analyses should:

1. Have a reasonable opportunity to produce 5 million barrels per day of liquid transportation fuel (approximately $80 \%$ of present oil import derived fuels) or their precursors that are compatible with the present infrastructure;

2. Utilize domestic carbon resources (coal, shale, or biomass-derived);

3. Directly incorporate or enable efficient grid introduction of intermittent renewable electric generation (solar, wind, or geothermal);

4. Demonstrate greenhouse gas emissions reduction for transport fuels and electric generation of greater than $25 \%$ from present levels;

5. Demonstrate, via integrated electricity and chemical production, how ( 3 and 4 ) above are achieved, how the nuclear island would be configured (number of reactors, grid integration, reactor / chemical plant operation paradigm, etc), sourcing of carbon, and related attributes;

6. Have potential for economic deployment via efficient heat and electrical energy integration within the system Proposals should address key enabling technology challenges, potential expansion of the SMR market as compared to baseload electric markets, and other attributes. Researchers are encouraged to examine published work on hybrid systems design and attributes (see list of references below).

Temperature Amplifying: Proposals that provide options for and assess implications of boosting the reactor outlet working fluid energy. Concepts are sought that could efficiently and effectively (in terms of cost, greenhouse gas emissions, and practical deployment potential) raise the temperature of a liquid or gas energy carrier from $250^{\circ} \mathrm{C}$ to $500-800^{\circ} \mathrm{C}$ (plus) in a manner suitable for use in an industrial process via a hybrid nuclear energy system;

Hydrogen Production via Nuclear Energy: Novel $\mathrm{H}_{2}$ production techniques that could be integral to systems described in (A) and/or using techniques as called for in (B);

Policy Strategy: Proposals that develop technical and sociopolitical strategies for integrating the disparate technologies and regulatory paradigms associated with complex, integrated nuclear hybrid systems are encouraged. Policy-related proposals should address key non-technical challenges to 
fielding a nuclear hybrid energy system and should propose research that will allow those challenges to be surmounted in a time and cost-efficient manner.

References: (Contact Richard Boardman 208-526-3083/Richard.Boardman@inl.gov for electronic copies)

DOE Report on the First Quadrennial Technology Review, September, 2011

Energy and Environmental Science, Large HES for Making low CO2 load-following power and synthetic fuels

Energy Policy, Using Excess Electric Generation Capacity to Make Synthetic Fuels at the National Scale

Energy, Multiple Hybrid Energy Systems for Load-Following and Offsetting Renewable Generations Variability

Energy, Dynamic Analysis of Hybrid Energy Systems under Flexible Operations and Variable Renewable Generation

Energy, Development of Multifunctional Energy Systems (MES)

INL/EXT-09-16942, Integration of High Temperature Gas Cooled Reactors into Industrial Process Applications

INL/EXT-11-23008, Integration of High Temperature Gas Cooled Reactors into Selected Industrial Process Applications

LBNL-1248E, Advanced Coal Wind Hybrid: Economic Analysis

ICAPP 2012, A Nuclear Wind/Solar Oil-Shale System for Variable Electricity and Liquid Fuels Production 